\title{
Osteomalacia caused by a phosphaturic mesenchymal tumor secreting fibroblast growth factor 23 (FGF-23): a case report
}

\author{
L. Ravarani' 1 , M. Faust ${ }^{1}$, A. Quaas², M. Bludau ${ }^{3}$, M. Schmidt', JC. Brüning ${ }^{1}$
}

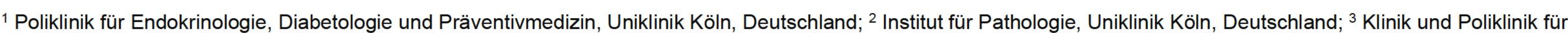
Allgemein -, Viszeral- und Tumorchirurgie, Uniklinik Köln, Deutschland; ${ }^{4}$ Klinik und Poliklinik für Nuklearmedizin, Uniklinik Köln, Deutschland

Background: Tumor-induced osteomalacia (TIO) is a rare acquired paraneoplastic syndrome clinically presenting with recurring fractures, muscular weakness and pain ${ }^{1}$. Laboratory values of affected patients are characterized by renal phosphate wasting and hypophosphatemia caused by an overexpression of fibroblast growth factor 23 (FGF- 23), a hormone belonging to the group of phosphatonins regulating phosphate and vitamin $D$ homeostasis ${ }^{2}$. Pathologically, it is secreted especially by small (and thus difficult to locate) mesenchymal tumors, leading to a significant delay from onset of (often debilitating) symptoms to diagnosis ${ }^{1}$. TIO was first described in 1947 and so far only approximately 300 cases have been reported in the literature ${ }^{3}$.



\begin{tabular}{|c|c|c|}
\hline Laboratory Values & Pre-Operative & Post-Operative \\
\hline $\begin{array}{c}\text { Serum Phosphate } \\
\text { (Ref } 0,81-1,45 \mathrm{mmol} / \mathrm{l})\end{array}$ & $0,36 \mathrm{mmol} / \mathrm{l}$ & $1,05 \mathrm{mmol} / \mathrm{l}$ \\
\hline $\begin{array}{l}\text { Urine Phosphate } \\
\quad(\text { Ref }<20 \%)\end{array}$ & $30 \%$ & $13,6 \%$ \\
\hline $\begin{array}{l}\text { 25-OH-Vitamin D } \\
\text { (Ref } 30-70 \mu \mathrm{g} / \mathrm{l})\end{array}$ & $48,3 \mu \mathrm{g} / \mathrm{l}$ & $45,0 \mu \mathrm{g} / \mathrm{l}$ \\
\hline $\begin{array}{l}\text { 1,25-OH-Vitamin D } \\
\text { (Ref } 25-86,5 \mathrm{pg} / \mathrm{ml} \text { ) }\end{array}$ & $12,2 \mathrm{pg} / \mathrm{ml}$ & $93,6 \mathrm{pg} / \mathrm{ml}$ \\
\hline $\begin{array}{c}\text { FGF-23 } \\
(\operatorname{Ref}<110 \mathrm{kRU} / \mathrm{L})\end{array}$ & $2100 \mathrm{kRU/L}$ & $35 \mathrm{kRU/L}$ \\
\hline Ire 1: Pre- and postoperativ & ratory results & \\
\hline
\end{tabular}

Case Report: We present a 41-year old female patient with a 4-year history of recurring metatarsal fractures and growing muscle pain. Workup showed (fig. 1) low levels of serum phosphate \& 1,25-OH Vitamin $D$ and an increased fractional excretion of urine phosphate. FGF-23 was increased 20-fold (measured value 2100 kRU/L Ref.: 110). Imaging diagnostics (ultrasound, DOTATATE-PET-CT, fig. 2) showed a $2.5 \times 2.5 \times 1 \mathrm{~cm}$ tumor located on the left pubic bone. The patient underwent surgery and in the histopathological work-up a benign mesenchymal tumor (fig. 3) was confirmed. After complete excision, the serum and urine phosphate normalized rapidly, FGF-23 levels decreased to normal within two weeks after surgery (35 kRU/L). The patient's symptoms greatly improved shortly after surgery and completely resolved over the course of 6 months.

Discussion: The aim of presenting this case report is to increase awareness that any patient showing hypophosphatemia, unexplained recurrent fractures and muscle weakness should undergo workup for TIO as this remains an extremely rare but potentially curable disease. 